\title{
Four ways forward in studying sex-based harassment
}

Jennifer Berdahl

\author{
Department of Sociology, University of British Columbia, Vancouver, Canada, and \\ Barnini Bhattacharyya \\ Sauder School of Business, The University of British Columbia, Vancouver, Canada
}

\begin{abstract}
Purpose - The purpose of this paper is to identify promising themes of the papers in the special issues of Equality, Diversity and Inclusion dedicated to advancing scholarship on sex-based harassment.

Design/methodology/approach - A conceptual overview of the research pertaining to these themes and an analysis of the special issues papers' contributions to these themes.

Findings - Four themes that represent important but relatively neglected lines of inquiry into sex-based harassment are identified. These are (1) the psychology of harassment, (2) organizational culture and networks, (3) the invisible majority and (4) the importance of collective action.

Originality/value - The paper offers an expert perspective on the state of research related to sex-based harassment and four themes that are important to moving it forward.
\end{abstract}

Keywords Sexual harassment, Sex-based harassment, Gender harassment, Sex discrimination

Paper type Conceptual paper

A shockwave hit the world in 2017, breaking widespread silence about sexual harassment. The year started with the inauguration of US President Donald Trump, caught on tape bragging, "when you're a star, they let you do it. You can do anything. ... Grab 'em by the pussy. You can do anything" (New York Times, 2016). The year ended with Time Magazine naming "The Silence Breakers" as Person of the Year "for giving voice to open secrets, for moving whisper networks onto social networks, for pushing all of us to stop accepting the unacceptable" (Zacharek et al.,2017) [1]. These silence breakers included widely admired and famous women who exposed one of the most powerful men in Hollywood, Harvey Weinstein, as a serial sexual harasser. As Anita Hill pointed out at the time, "Sexual harassment is about power, and it has taken women of extraordinary power to overcome the disadvantage that most accusers face" (Mayer, 2017). Under the safety of their voices, social media feeds filled with family members, friends and coworkers saying \#MeToo. The movement went worldwide, and for the first time in history, people seemed to err on the side of believing victims instead blaming them, of denouncing harassers instead of defending them.

Sexual harassment went from being the butt of jokes and a marginalized topic to being a central concern in need of expert input. People wondered how sexual harassers (usually men) could get away with such abusive behavior for so long, even when the abuse was an open secret; how so many people (usually women) could be harassed and career damaged right under our noses; why the problem could go on for so many decades without improvement or redress; and why education, training, policies, reporting structures and disciplinary systems had failed so miserably to address the problem that had been named and outlawed for

(C) Jennifer Berdahl and Barnini Bhattacharyya. Published by Emerald Publishing Limited. This article is published under the Creative Commons Attribution (CC BY 4.0) licence. Anyone may reproduce, distribute, translate and create derivative works of this article (for both commercial and non-commercial purposes), subject to full attribution to the original publication and authors. The full terms of this licence

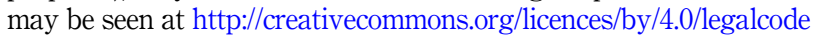

Received 15 March 2021 Revised 24 March 2021 Accepted 24 March 2021

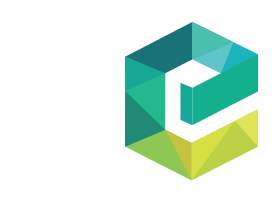

Equality, Diversity and Inclusion: An International Journal Vol. 40 No. 4,2021 pp. $477-492$ Emerald Publishing Limited 2040-7149 
EDI

40,4

decades. The \#MeToo Movement prompted questions of \#WhatNow and declarations of \#TimesUp: A renewed and concerted effort to condemn harassment and to stop it from continuing, once and for all. As part of this effort, Peggy Stockdale, Faye Crosby, Myrtle Bell, and Jennifer Berdahl launched the special issues of Equality, Diversity and Inclusion, From Me Too to What Now: Advancing Scholarship on Sex Harassment: A Persistent Problem (Issue 1; Stockdale et al., 2020a) and Making Progress (Issue 2; Crosby et al., 2021).

In this paper, we highlight and elaborate upon four themes from the articles in these special issues that represent important but relatively neglected lines of inquiry into sexual harassment. These are (1) the psychology of harassment, (2) organizational culture and networks, (3) the invisible majority and (4) the importance of collective action. We review each in turn, considering their status in the literature, contributions made by papers in this special issue and promising directions for future research. We conclude with the observation that the answer to \#WhatNow is found in its precursor, \#MeToo: Like Dorothy and the ruby slippers in The Wizard of $\mathrm{Oz}$, we have had the power to do something about sexual harassment, we just needed our fairy godmothers, so to speak, to help us realize it. The man behind the curtain is not so powerful, after all, when we pull away the curtain and raise our collective voices against him.

\section{The psychology of harassment}

Relatively little empirical research has studied the psychology of sexual harassment. This psychology has largely been assumed, especially by lay audiences and those new to the topic, as a desire for sexual expression or gratification whose fulfillment is made possible by power. The case of Harvey Weinstein fits this narrative, with the powerful movie mogul sexually harassing young and beautiful actresses and ensuring their silence with career threats and legal payouts. This case that ignited the worldwide \#MeToo Movement is readily recognizable as a form of abuse based on sex. But research on sexual harassment challenges this prototype and its presumed psychology.

Sexual harassment, or more aptly, sex-based harassment, is defined as behavior that derogates, humiliates or coerces a person(s) based on sex (Berdahl, 2007a; National Academies of Sciences, Engineering and Medicine, 2018). This includes sexual coercion (also known as quid-pro-quo harassment) and unwanted sexual attention, but by far the most common form of harassment based on sex is gender harassment: sexist comments, jokes and materials that degrade the victim(s) based on sex (female or male) and/or gender (femininity or masculinity) (e.g. Cortina and Areguin, 2021; Fitzgerald et al., 1988, 1995; Leskinen et al., 2011; Shute et al., 2008). Compared to sexual coercion and unwanted attention, gender harassment is more obviously motivated by dominance than sexual motives. All three forms of sex-based harassment function to degrade and control (usually) women and to keep them out of, or down in, male-dominated jobs, roles and spaces (e.g. Berdahl, 2007a; Cortina and Areguin, 2021; Franke, 1997; MacKinnon, 1976). It is not a far leap to conclude that these effects are intended.

The men most likely to sexually harass women endorse sex stereotypes, sexist attitudes, gender and other forms of inequality, and consider being "a man" central to their identity; importantly, their harassing behavior is triggered by threats to this identity (Alonso, 2018; Dall'Ara and Maass, 1999; Kasumovic and Kuznekoff, 2015; Maass et al., 2003; Siebler et al., 2008). This helps to explain why those most likely to threaten male identity are most targeted for sexual harassment, including women in male-dominated jobs (Berdahl, 2007b; Fitzgerald et al., 1999; Glomb et al., 1999; Gruber, 1998; Mansfield et al., 1991), women in positions of power (e.g. McLaughlin et al., 2012; Folke et al., 2020), ambitious, assertive, confident and outspoken women (Berdahl, 2007b; Bai et al., 2014), and feminist women (Dall'Araand Maass, 1999; Holland and Cortina, 2013; Maass et al., 2003; Siebler et al., 2008). Men also target other 
men for sex-based harassment when their manhood is threatened (Alonso, 2018), and are especially likely to target gender nonconforming men, such as men they perceive to be queer or feminized (Berdahl et al., 1996; Berdahl and Moon, 2013; Konik and Cortina, 2008; Stockdale, 2005; Stockdale et al., 1999; Trades Union Congress, 2019; Waldo et al.,1998).

Research into the psychology of men who sexually harass thus shows their behavior is triggered by a desire to restore, protect or enhance a sense of male identity, or "manhood." In other words, sexual harassment is more about exploiting gender for power goals than it is about exploiting power for sexual goals (Berdahl, 2018). Because "being a man" is synonymous with being powerful (e.g. Connell, 1987; Connell and Messerschmidt, 2005; Sidanius and Pratto, 2001), it is not surprising that "power hungry" men are especially prone to harass. Sexual harassers tend to automatically link power with sex (Bargh et al., 1995), and harassment is highly correlated with bullying and other acts of dominance (e.g. Glick et al., 2018; Lim and Cortina, 2005; Robotham and Cortina, 2020). One could say that sexual harassers "get off" on dominating others, sexually and otherwise. It is easy to get confused by the "sexual" part of some forms of harassment and lose sight of the core "dominance" component of them. In Figure 1, we illustrate how there are plenty of consensual sexual behaviors that do not involve attempts to dominate, derogate and humiliate; it is not the sexual nature of a behavior that makes it harassing, it is the dominant nature of a behavior that does. What may be consensual on the left-hand side of the figure becomes coercive on the right as the ability of the other party to consent becomes compromised and the initiator of these behaviors holds organizational, economic, social, physical or other forms of power or status over the target. It is important to remember that sexual harassment is a form of bullying and should be treated as such (Potter, 2018; Shute et al., 2008, recommend the term "sexual bullying").

Two papers in this special issue focus on the psychology of heterosexual pursuit and coercion (rather than the more common gender harassment) at work. Both online experiments show that perpetrator power increases the approval and likelihood of initiating sexual behavior toward an other-sex person at work. Klein et al. (2021) show that customer power (the ability to tip) increased men's likelihood to find sexual behavior toward a female bartender acceptable. Stockdale et al. (2020b) find that priming power increased people's (especially men's) likelihood to ask an underling for sexual favors or to persistently pursue a
Four ways forward

479

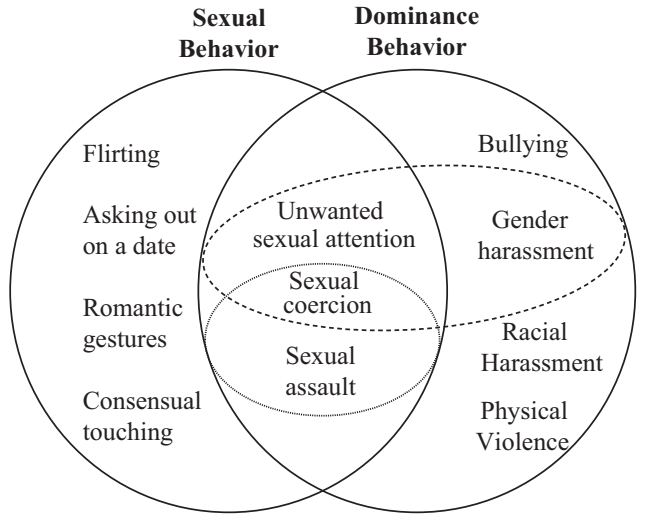

Note(s): Dashed line $=$ Sexual harassment (harassment based on sex)

Dotted line $=$ Sexual abuse
Figure 1.

Distinguishing between sexual

behavior and dominance behavior 
EDI

40,4 sexual relationship with a coworker. Interestingly, Klein and colleagues found that perceptions of a female bartender's agency (her ability to choose what she wears to work) increased perceptions of her manipulativeness and men's approval of a customer behaving sexually toward her. This resonates with research showing that it is agentic and powerful women who are targeted most for sexual harassment (e.g. Berdahl, 2007b; McLaughlin et al., 2012). Stockdale and colleagues also showed that "power hungry" people (high in the "dark triad" personalities of narcissism, Machiavellianism and psychopathy, which men were higher on than women) were more likely to link feeling powerful with feeling sexy (which men were more likely to do than women), which predicted a willingness to engage in inappropriate heterosexual behavior toward a supervisee or coworker (which men were more willing to do than women).

These studies strengthen evidence of the importance of power in the psychology of harassment. Understanding how power motivates sexual harassment in the minds of harassers, and legitimates harassment in the minds of observers, is key to preventing and combating it. Future research can build on this by further exploring the psychological links between of power and sex, and particularly how and when these links are gendered. Any understanding of the psychology of harassment based on sex must be careful not to ignore the social structures, norms and dynamics of "doing gender" (West and Zimmerman, 1987) that shape and define the behavior. Erasing gender from theoretical and empirical analyses does not make it go away; it merely obscures and prevents a fuller understanding of sexbased harassment. Social identities used to harass and bully others (e.g. gender, race and class) are stratified by status and power; attempts to exploit and abuse these identities to dominate others must necessarily be understood in the context of these forms of stratification.

Another fruitful avenue of research is to study the likelihood to sexually harass alongside the likelihood to racially harass and bully others, as well as to engage in other self-serving acts of misconduct. Sexual harassment is highly correlated with ethnic and racial harassment and bullying in studies of individual experiences (e.g. Berdahl and Moore, 2006; Glick et al., 2018); are these behaviors also positively correlated within perpetrator behavior? Because sexual harassers try to dominate others based on gender, they might also be likely to try to dominate others based on stratified social identities such as race, ability, age and class. One only has to think of the way the 45th US President derogated women who stood up to him along with racial and ethnic minorities, immigrants and disabled people to imagine how a tendency to humiliate and degrade others based on marginalized social identities may go hand-in-hand. If harassers tend to have "dark triad" personalities (Stockdale et al., 2020b), they are also likely to engage in other forms of misconduct such as lying, stealing, plagiarism, embezzlement and other forms of corruption, consistent with the "Al Capone Theory" of sexual harassment (Aurora and Honeywell, 2017).

Finally, a better understanding of the rewards of harassment for its perpetrators would lend insight into why they harass and what might be done to stop them from harassing. Maass et al. (2003) found that men felt more like a "man" after harassing a woman (i.e. sending her degrading pornography) who had made feminist statements, thus restoring men's sense of male identity and status after it was threatened. Does harassment enhance not only the harasser's sense of status and power, but their actual status and power in the workplace? Does it make others admire or fear the harasser(s), or both, and how does this depend on the social context in which the harassment takes place? Further understanding the social and psychological rewards of harassment can help to identify how these rewards might be removed so that harassment it is no longer an attractive option for perpetrators. 


\section{Organizational culture and networks}

Any understanding of the psychology of harassment must involve the social context in which it takes place, as it is this context that motivates and rewards the behavior. Attempts to study harassment without theorizing context leads to reductionistic accounts, like early theories viewing sexual harassment as a biological inevitability ("boys will be boys") or a simple abuse of power for sexual gratification (e.g. Studd and Gattiker, 1991). Decades of scholarship have challenged these accounts but it is easy to default to "gender blind" assumptions that ring true with patriarchal norms and ideology. But because understanding the social contexts in which sexual harassment thrives (and does not) is key to understanding why it occurs in the first place, there is luckily a relative abundance of scholarship addressing how societal norms, organizational demographics, and more recently, climate and culture, encourage or discourage the behavior.

Sex-based harassment, like other forms of identity-based harassment, is made possible by social constructions of the identities at play and their dynamics of inequality (Maass et al., 2003; Robotham and Cortina, 2020). The motive and ability to harass others based on sex is rooted in sexual inequality, like the motive and ability to harass others based on race is rooted in racial inequality. Male political, economic, social and physical dominance over women motivates, enables and supports men's harassment of women. To pretend that men and women can enact the same sexist behaviors, or that they would mean the same thing if they did, is misleading. Sexual harassment is, fundamentally, a gendered expression of power (Uggenand Blackstone, 2004), embedded in patriarchal systems of control in which men use sex-based power to dominate women (and marginalized men). We know that sexual harassment is mostly perpetrated by men against women, that when men are harassed it is often by other men, that sexual harassment usually involves misogynist put-downs (including the harassment of men), that it mostly takes place in male-dominated industries and workplaces, that male subordinates harass female superiors, and that gender nonconformers are particularly targeted for harassment. In short, sexual harassment is a technology of sexism, keeping women (and marginalized men) down in, and out of, desired workplaces and positions of power (e.g. Franke, 1997; Stockdale et al., 1999). And we know from the psychology of harassment that it is about protecting or enhancing the harassers' sense of status based on sex - most often men's ability to feel powerful as "men" (e.g. Alonso, 2018; Maass et al., 2003).

It is no wonder, then, that workplace cultures that valorize men and masculinity and denigrate women and femininity witness the highest rates of sexual harassment (Berdahl et al., 2018). Recent research shows that workplaces with masculinity contest cultures, in which status is defined and achieved by outperforming others in masculine characteristics, have significantly higher rates of sexual harassment as well as racial harassment, bullying, toxic leadership, low psychological safety and other practices that pit workers against each other (Glick et al., 2018; Matos et al., 2018; Workman-Stark, 2020). Unsurprisingly, work environments characterized by masculinity contest cultures also have few women in management (Glick et al., 2018) and their workers suffer significantly higher rates of burnout and lower levels of organizational identity, dedication and performance, and mental and physical health (Glick et al., 2018; Koc et al., 2021). Masculinity contest culture, in short, describes many toxic work environments featured on the front pages of newspapers as marked with harassment and scandal (e.g. Uber, Fox News, and more recently New York Governor Andrew Cuomo's office).

Three papers in this special issue address how workplace climate and networks shape organizational contexts that help to prevent or promote sexual harassment. Perry et al. (2021) present a compelling conceptual model of how inclusive leaders who facilitate belongingness, value uniqueness in employees and prevent exclusion are likely to generate climates of inclusiveness and reduce the likelihood of sexual harassment and other forms of
Four ways forward 
EDI

40,4

482

mistreatment. Such work environments are likely to remove "who's in and who's out" divisions that pit workers against each other in a competition for status, thus also removing motives to dominate and denigrate others, or to promote oneself, based on socially unequal identities. The studies by Robotham and Cortina (2020) support this idea with empirical evidence from the military and a sample of working adults, showing that climates of respect reduce both sexual as well as ethnic forms of identity-based harassment.

Far from the climates of inclusiveness and respect that reduce sexual harassment, Cunningham et al. (2021) illustrate how successful sexual harassers build climates of exclusion and disrespect by cultivating "networks of complicity" in their work environments. In a qualitative study of in-depth interviews with employees in work environments containing at least one serial harasser, these authors find that harassers build networks in which they are central players and power brokers, perpetrate myths and misinformation, and shield themselves from accountability. These networks of complicity protect sexual harassers from sanction and enable their behavior to continue by having active enablers who sabotage those who try to expose the harasser, passive enablers who turn a blind eye to or rationalize the behavior, and bystanders who fail to take action. The harm done by network members is often described by victims in this study as worse than the harassment itself, consistent with other accounts (e.g. Merlo, 2013). These networks of complicity metastasize as perpetrators' power grows and they place unqualified people loyal to them into positions of power, creating toxic climates devoid of trust and cooperation. These networks echo Brown and Battle's (2020) argument in Volume 1 of these special issues that people fear ostracism from their social networks at work for disclosing harassment and abuse in the workplace. This ostracism may be more scary and painful than the harassment itself (O'Reilly et al., 2015), which can help to explain why so many victims and bystanders remain silent about sexual harassment.

These contributions show why and how sexual harassment must be conceptualized beyond the individual perpetrator. Even in cases in which there is an individual perpetrator, such as Harvey Weinstein, there is often a social network surrounding and protecting that perpetrator that is at least complicit in his abuse, and often abusive itself when it acts to shut down, slander, and shun victims and whistle blowers. Sexual harassment can also become the modus operandi of workplace culture, in which it becomes normative to make and laugh at sexist jokes and comments, share offensive materials, put down women, distance oneself from all things feminine, tease men about their masculinity, sexually objectify new recruits and otherwise create a hostile working environment based on sex. Such workplace cultures take a village, so to speak, to create and to perpetuate, with many people (and complicit bystanders) sprinkling small acts of unkindness that add up to a workplace that is hostile to women and marginalized men.

A promising direction for future research would be to study the dynamics of workplace harassment in the broader social context of multiple actors, such as Cunningham et al.'s (2021) active enablers, passive enablers and bystanders. Do harassers tend to have, or harass with, a "deputy" who backs them up, or a "posse" that surrounds and protects their behavior? How can networks of complicity, or network silence, be disbanded or broken (Herschcovis et al., 2021)? Mapping the full range of victims' experiences - not just the harassment itself, but their treatment by others during and after it - will help to more fully understand how such behavior can act as a form of bullying and mobbing at work. A challenging but crucial direction for future research is to better understand how organizational change can take place to convert networks of complicity and climates of exclusion and disrespect into networks of support and climates of inclusion and respect. There are excellent examples of organizational change studies addressing related concepts, such as enhancing psychological and physical safety and improving work-life balance (e.g. Ely and Meyerson, 2010; Kossek et al., 2014; Kellogg, 2011; Perlow, 2012), that could inform such research. 


\section{The invisible majority}

While research has documented that sexual harassment is particularly common against women who encroach on male domains and identities, a large proportion of women are overlooked in research on sexual harassment, either because they work in traditionally female jobs (e.g. nursing, domestic work, childcare) and/or because they do not possess prototypical gender identities (e.g. women of color, queer women, immigrant women). This is despite evidence that many such women are particularly susceptible to sexual and other forms of harassment (e.g. Berdahl and Moore, 2006; Silverschanz et al., 2008). Of note, even though \#MeToo was coined by Tarana Burke, a Black American activist, to raise awareness of sexual abuse experienced by young Black girls, the term was appropriated by Alyssa Milano, a White American actress, to give voice to survivors in the wake of the sexual harassment and abuse allegations against Harvey Weinstein (who has now been convicted of his crimes). The hashtag was widely used across social media without giving due credit to Burke. Women of color saw this as an erasure of Burke's lifelong work as well as of the experiences of assault on women of color, fitting the pattern of intersectional invisibility experienced by women of color who lack even the low levels of personal and social capital offered prototypical women in a patriarchal world (Buchanan and Settles, 2019; PurdieVaughns and Eibach, 2008).

Several papers in this special issue shed light on sexual harassment experienced by the invisible majority. In her paper, Fitzgerald (2021) examines the sexual harassment experiences of women in low-wage jobs, noting that low-income women in America are especially vulnerable to sexual harassment because of their position at the intersection of low power and gender, yet they receive very little scholarly attention, media coverage or legal support. These women, who are some of the lowest paid and most disenfranchised workers in America, experience acute sexual harassment. Agricultural workers, who are mostly immigrants, are sexually assaulted on farms; subminimum wage restaurant workers are sexually harassed by customers; single mothers in low-income housing are sexually coerced by landlords and janitorial workers are harassed by their bosses. The paper by Fitzgerald illustrates that these groups of women fall through the cracks of legal systems and that their experiences of sexual violence are rendered invisible in mainstream narratives and perspectives.

Even when sexual harassment against women who belong to vulnerable or marginalized groups is acknowledged, their experiences tend to be discounted. Klein et al. (2021) found that a female bartender was perceived as more manipulative when she could earn tips and decide how to dress, and that sexual harassment against her was perceived as more legitimate as a result. This reinforces the victim-blaming notion that women "ask for it," which makes women in low-paying service industries, where most workers are dependent on tips to make living wages, not only more vulnerable to harassment but also less likely to be able to seek recourse when they do.

What is important to note is that there is much overlap between the marginalized groups studied by Fitzgerald (2021) and by Klein et al. (2021), and women who belong to racial minority groups. Most women engaged in low-paid work are racialized, and are often immigrants, placing them very low in the hierarchy of power and status. Critical race scholars have noted that women of color are rendered invisible in many social realms such as workplaces, the media or academic research, due to their nonprototypical gender and racial identities (e.g. Buchanan and Settles, 2019; Purdie-Vaughns and Eibach, 2008), and this phenomenon appears to be replicated within the narrative around sexual harassment.

Thus far, there is a dearth of research studying the experiences of sexual harassment that women of color and women with other marginalized identities are subjected to (for exceptions see Buchanan et al., 2018; Cortina, 2001; Waugh, 2010; Woods et al., 2009). This highlights the importance of an intersectional lens in understanding and examining sexual harassment at
Four ways forward

\section{3}


EDI

40,4

484

work. Intersectionality theory is a multiple-axis framework to study social experiences and focuses, in particular, on the multiple ways in which identities interact to shape people's experiences (Crenshaw, 1989). An intersectional lens sheds light on how structural power can create social hierarchies which affect whose experiences are more salient and whose are rendered invisible (McCall, 2005; Purdie-Vaughns and Eibach, 2008). The term "intersectionality" was coined by Kimberlé Crenshaw to draw attention to Black women's experiences at the margins of their racial and gender identities (Crenshaw, 1989), and this framework is now used widely by scholars to study multiple marginalized subjects (e.g. Bhattacharyya and Berdahl, 2018; Bowleg, 2013; Buchanan and Settles, 2019; McCluney and Rabelo, 2019; Purdie-Vaughns and Eibach, 2008; Rosette et al., 2016; Shields, 2008; Smith et al., 2019).

In their paper examining antisexual harassment efforts in Lebanese workplaces, Karam and Ghanam (2021) use an intersectional framework to unpack power dynamics in the global South. They show how opposition to sexual harassment in Lebanon has been shaped by ideas both within and outside of the Middle East. This includes overlooking the experiences of immigrant women and domestic servants, who are not just implicitly, but explicitly omitted from discussion and consideration by the legal, business and academic panels studied by Karam and Ghanam. These authors also compellingly argue that despite the fact that sexual harassment is a global phenomenon, frameworks of sexual harassment and power that exist in the Global North do not fit neatly into other contexts, and therefore highlight the importance of alternative frameworks for conceptualizing and studying sexual harassment and power.

Heck (2020), in her paper on the discussion between Kimberlé Crenshaw and Anita Hill, notes the acute urgency of understanding sexual harassment from an intersectional lens by bringing to our attention the harmful consequences of having failed to do so thus far. The lack of the operationalization of intersectionality in the \#MeToo movement has left out the unique experiences and voices of women of color and women with other marginalized identities. This has prevented women of color, for example, the Black women victims of R. Kelly, from receiving justice. Another significant outcome of this has been more focus on the condemnation of individuals, which, although necessary, takes attention and resources away from dismantling the structures of power that allow sexual harassment to continue unabated.

It is important to adopt intersectionality theory to study sexual harassment. Research has not only found that women who belong to the unseen majority are disproportionality vulnerable to sexual harassment and violence (Fitzgerald, 2021), but has shown that they have uniquely different experiences. For instance, Black women report racialized sexual harassment (Buchanan, 2005), women of color report experiencing exoticization (Bhattacharyya and Berdahl, 2018) and queer women are punished for deviating from patriarchal gender roles (Brassel et al., 2019; Konik and Cortina, 2008). In fact, much of the experiences of women with multiple marginalized identities, such as queer women of color, or Latina immigrant agricultural workers, are yet to be documented or studied (e.g. Brassel et al., 2020). Studies also find that sexual harassment claims of women with marginalized or nonprototypical identities tend to be perceived as less credible and legitimate (Goh et al., 2021; Sambaraju, 2020), and as even less psychologically harmful, compared to their prototypical counterparts (Goh et al., 2021), even though such women are the ones most likely to be sexually harassed. These complexities cannot be captured by studying the experiences of one class of women or by using a single-axis theoretical framework.

Future research should thus turn more attention to understanding the experiences of the invisible majority - women in low-wage jobs with little protection, immigrant women, women of color and how their experiences might differ depending on their racialization, and queer women. Though sexual coercion and assault is a relatively rare phenomenon in most studies, 
which show that gender harassment is the most common form of harassment based on sex, it is likely that the relative prevalence, severity and explicitness of sexual harassment is higher in less powerful and more marginalized samples that constitute the invisible majority. For example, sexual assault may be seen as something harassers can more easily get away with against more vulnerable and marginalized populations, whereas gender harassment may be a "softer" tool for degrading more privileged and powerful women, consistent with intersectional theorizing around the different ways that women of privilege and marginalized women are subjugated by dominant groups of men (e.g. Hurtado, 1989).

\section{Collective action}

Collective action brought us the \#MeToo movement and is also the best answer to \#WhatNow, pointing the way forward to tackling sexual harassment. If there is one thing the \#MeToo movement has shown us, it is that collective action can be powerful enough to take on the law, fame, wealth and power in the comeuppance of perpetrators. By allowing survivors to break the silence around their abuse, \#MeToo was instrumental in helping them reclaim power from their harassers and in getting support from others in condemning these harassers and their behavior. People who believed they were alone in their concerns or experiences were able to find each other and to build networks of solidarity and support.

In their paper, Leopold et al. (2021) illustrate how the informal \#MeToo movement changed attitudes and understandings of sexual harassment in ways that formal legal and organizational frameworks were unable to for decades. Though solutions to the problem have long been assumed to rest in laws, policies and their enforcement, these authors discuss how a focus on compliance has not led to much progress and change for years but how "millions of tweets, retweets, and other social media postings of sexual harassment victims sharing their stories" led to substantial change within months. The \#MeToo movement shifted assumptions about the acceptability of sexual harassment, the believability of victims and awareness of harassment as a pervasive and destructive problem. The authors conclude that this change in awareness did more to deter and punish harassment than laws and policies can do alone.

Amber et al. (2020) reveal a mechanism that helps to explain the quick spread of the \#MeToo movement. Their research shows that stories of sexual harassment in the media predicted women's memories and interpretation of their own past experiences of being sexually harassed. This provides context for the exponential impact of the \#MeToo hashtag on social media, which triggered millions of people to remember and publicly disclose their experiences of harassment. The ripple effect of this was felt worldwide, both in terms of building community and in holding harassers accountable. The consequences of triggering such recall, recognition and solidarity of the harm done by sexual harassers is likely a big reason so much effort has been put into silencing those who would speak out about harassment and into smearing those who do (Cunningham et al., 2021; Herschovis et al., 2021).

Fear of retaliation and backlash prevents victims from disclosing their abuse (Cortina and Magley, 2003), leaving them with feelings of shame and isolation. \#MeToo broke the cycle by creating space for women to disclosure as well as to find social support. As Brown and Battle (2020) discuss in their paper, a fear of ostracism in particular can prevent disclosure. They note that the \#MeToo movement, in its focus on breaking silence and building community, has reduced this fear of being ostracized, thus mitigating a fundamental barrier to reporting sexual harassment. Schneider and Carpenter (2020) find evidence of this through their analysis of \#MeToo Tweets, showing that tweets that indicated positive social reactions signaled validation and believing in survivors, offering support and calling for social change.

However, the systems and structures that allow and perpetuate sexual harassment still persist. The study by Cunningham et al. (2021) shows how networks of complicity enable 
EDI

40,4

sexual harassment to persist and even grow, even when many know about the abuse. These organizational networks are built to protect perpetrators, not victims, of sexual harassment. Again, the solution to dismantling such structures lies outside of them. A recommendation that is often put forth (and summarily rejected, of course, by organizations preferring to police - and cover up - their own misdeeds), is to establish an external watchdog agency with no ties to or conflicts of interest with the professional networks in which the harassment to be investigated takes place (e.g. Lang and Dallaire, 2013; Hershcovis et al., 2021). Such an external agency could independently receive complaints, conduct investigations and determine penalties, bypassing the networks that are motivated to shield the perpetrator, to protect the image of the organization and to encourage silence around harassment. An example of this is US Safe Sport, charged with investigating allegations of abuse in athletics and created in the wake of the revelation that Larry Nassar had sexually abused hundreds of female gymnasts in his role as head doctor for USA Gymnastics. Future research could explore the effectiveness of such agencies and develop an understanding of best practices around such investigations and their outcomes.

Some individuals and organizations have also started to experiment with introducing allegation escrows - "a neutral third-party that collects allegations anonymously, matches them against each other, and de-anonymizes allegers only after de-anonymity thresholds (in terms of number of co-allegers), pre-specified by the allegers, are reached" (Arun et al.,2018). The advantage of an allegation escrow is that it is focused on protecting individual victims of sexual harassment and operating to make reporting safer and more impactful through anonymity and strength in numbers. Future research could also study the effectiveness of allegation escrows in getting victims and bystanders to report harassment, and the tipping points for complaints in assessments of the probability of evidence and the ability to protect victims from retaliation and instead shut down the harassing behavior.

Finally, mobilizing social activism and systematic advocacy can play an important role in bringing about structural change. The Coalition of Immokalee Workers in Florida (Fitzgerald, 2021), for example, set up via migrant-farmworker community organizing, has continually organized action against sexual violence toward farmworkers by supervisors, (among other activities). As of 2020, they conduct ongoing education around sexual harassment focused on empowerment, monitoring one's rights and filing complaints, and removing secrecy. Their work, a combination of organized action and reform, has begun to create a culture of protecting workers, reporting perpetrators and building communities of social support. On the other side of the world, persistent and massive protests across India after a brutal gang rape of a woman in 2012 led to an expedited police investigation and creating an independent judicial committee to introduce quicker investigation and prosecution processes, and reforming existing sexual assault laws in India. More progressive laws were passed and six new fast-track courts were established a year later.

In short, collective action is likely the most powerful tool for combating sexual harassment and changing laws, workplace practice and public opinion about its acceptability. Much more research needs to be done into how collective action can be effectively mobilized and ensconced in societal institutions and attitudes so that investigations are effective and fair and the rights of the accused are protected while the voices of the abused are heard and acted upon to heal those affected and to prevent future victims.

\section{Conclusion}

In this paper, we identified four themes from the articles in the special issues of Equality, Diversity and Inclusion on advancing research on sex harassment: (1) the psychology of harassment, (2) organizational culture and networks, (3) the invisible majority and (4) the importance of collective action. We explained how these oft neglected lines of inquiry promise 
to shed light on why harassment based on sex occurs, in which contexts, by whom, against whom and why collective action, like the \#MeToo movement, is the best way to end it. As one feminist advocate said (Feldt, 2012, p. 242), "The path to big, systemic change is collective action. That takes Sister Courage."

\section{Note}

1. Interestingly, the one other time a group of women was Time's Person of the Year was in 2002, when "The Whisteblowers" were celebrated for outing organizational corruption and failure and making "it clear that when dedicated to doing the right thing, anyone can make a difference" (Semuels, 2002).

\section{References}

Alonso, N. (2018), "Playing to win: male-male sex-based harassment and the masculinity contest", Journal of Social Issues, Vol. 74 No. 3, pp. 477-499, doi: 10.1111/josi.12283.

Amber, B., Dinh, T.K., Lewis, A.N., Trujillo, L.D. and Stockdale, M.S. (2020), "High-profile sexual misconduct media triggers sex harassment recall and reinterpretation", Equality, Diversity and Inclusion: An International Journal, Vol. 39 No. 1, pp. 68-86, doi: 10.1108/EDI-12-2018-0222.

Arun, V., Kate, A., Garg, D., Druschel, P. and Bhattacharjee, B. (2018), "Finding safety in numbers with secure allegation escrows", arXiv preprint arXiv:1810.10123.

Aurora, V. and Honeywell, L. (2017), "The Al Capone theory of sexual harassment", available at: https://blog.valerieaurora.org/2017/07/18/the-al-capone-theory-of-sexual-harassment/amp/ (accessed 17 March 2021).

Bai, F., Berdahl, J.L. and Schieman, S. (2014), “The "ambition gap” explained: workplace mistreatment as a function of gender, ambition, and rank", Academy of Management Proceedings, Vol. 2014 No. 1, p. 17425, doi: 10.5465/ambpp.2014.17425abstract.

Bargh, J.A., Raymond, P., Pryor, J.B. and Strack, F. (1995), "Attractiveness of the underling: an automatic power $\rightarrow$ sex association and its consequences for sexual harassment and aggression”, Journal of Personality and Social Psychology, Vol. 68 No. 5, p. 768.

Berdahl, J.L. (2007a), "Harassment based on sex: protecting social status in the context of gender hierarchy", Academy of Management Review, Vol. 32 No. 2, pp. 641-658.

Berdahl, J.L. (2007b), “The sexual harassment of uppity women”, Journal of Applied Psychology, Vol. 92 No. 2, pp. 425-437.

Berdahl, J.L. (2018), "Harassment and contest culture in organizations", Presentation at the, Saïd Business School, University of Oxford, Oxford.

Berdahl, J.L. and Moon, S.H. (2013), "Workplace mistreatment of middle class workers based on sex, parenthood, and caregiving", Journal of Social Issues, Vol. 69 No. 2, pp. 341-366.

Berdahl, J.L. and Moore, C. (2006), "Workplace harassment: double jeopardy for minority women", Journal of Applied Psychology, Vol. 91 No. 2, pp. 426-436.

Berdahl, J.L., Magley, V.J. and Waldo, C.R. (1996), "The sexual harassment of men?: Exploring the concept with theory and data", Psychology of Women Quarterly, Vol. 20 No. 4, pp. 527-547.

Berdahl, J.L., Cooper, M., Glick, P., Livingston, R.W. and Williams, J.C. (2018), "Work as a masculinity contest", Journal of Social Issues, Vol. 74 No. 3, pp. 422-448.

Bhattacharyya, B. and Berdahl, J.L. (2018), "Can you see me? An intersectional study of women of colors' experiences of and responses to invisibility at work", Academy of Management Annual Conference, Chicago.

Bowleg, L. (2013), “'Once you've blended the cake, you can't take the parts back to the main ingredients": black gay and bisexual men's descriptions and experiences of intersectionality", Sex Roles, Vol. 68 No. 11, pp. 754-767. 
EDI

40,4

Brassel, S.T., Settles, I.H. and Buchanan, N.T. (2019), "Lay (mis) perceptions of sexual harassment toward transgender, lesbian, and gay employees”, Sex Roles, Vol. 80 No. 1, pp. 76-90.

Brassel, S.T., Davis, T.M., Jones, M.K., Miller-Tejada, S., Thorne, K.M. and Areguin, M.A. (2020), "The importance of intersectionality for research on the sexual harassment of Black queer women at work", Translational Issues in Psychological Science, Vol. 6 No. 4, pp. 383-391.

Brown, S.E. and Battle, J.S. (2020), "Ostracizing targets of workplace sexual harassment before and after the\# MeToo movement", Equality, Diversity and Inclusion: An International Journal, Vol. 39 No. 1, pp. 53-67.

Buchanan, N.T. (2005), "The nexus of race and gender domination: the racialized sexual harassment of African American women”, in Morgan, P. and Gruber, J. (Eds), In the Company of Men: Rediscovering the Links between Sexual Harassment and Male Domination, Northeastern University Press, Boston, pp. 294-320.

Buchanan, N.T. and Settles, I.H. (2019), "Managing (in) visibility and hypervisibility in the workplace", Journal of Vocational Behavior, Vol. 113, pp. 1-5.

Buchanan, N.T., Settles, I.H., Wu, I.H.C. and Hayashino, D.S. (2018), "Sexual harassment, racial harassment, and well-being among Asian American women: an intersectional approach", Women and Therapy, Vol. 41, pp. 261-280.

Connell, R.W. (1987), Gender and Power: Society, the Person, and Sexual Politics, Stanford University Press, Stanford, CA.

Connell, R.W. and Messerschmidt, J. (2005), "Hegemonic masculinity: rethinking the concept", Gender and Society, Vol. 19, pp. 829-859.

Cortina, L.M. (2001), “Assessing sexual harassment among Latinas: development of an instrument”, Cultural Diversity and Ethnic Minority Psychology, Vol. 7, pp. 164-181.

Cortina, L.M. and Areguin, M.A. (2021), "Putting people down and pushing them out: sexual harassment in the workplace", Annual Review of Organizational Psychology and Organizational Behavior, Vol. 8, pp. 285-309.

Cortina, L.M. and Magley, V.J. (2003), "Raising voice, risking retaliation: events following interpersonal mistreatment in the "workplace"', Journal of Occupational Health Psychology, Vol. 8 No. 4, p. 247.

Crenshaw, K. (1989), "Demarginalizing the intersection of race and sex: a black feminist critique of antidiscrimination doctrine, feminist theory, and antiracist politics", University of Chicago Legal Forum, pp. 139-67.

Crosby, F.J., Stockdale, M.S., Bell, M.P. and Berdahl, J.L. (2021), "Guest editorial: from me too to what now: advancing scholarship on sex harassment issue 2: making progress", Equality, Diversity, and Inclusion: An International Journal.

Cunningham, P., Drumwright, M.E. and Foster, K.W. (2021), "Networks of complicity: social networks and sex harassment", Equality, Diversity and Inclusion: An International Journal.

Dall'Ara, E. and Maass, A. (1999), "Studying sexual harassment in the laboratory: are egalitarian women at higher risk?”, Sex Roles, Vol. 41 No. 9, pp. 681-704.

Ely, R.J. and Meyerson, D.E. (2010), "An organizational approach to undoing gender: the unlikely case of offshore oil platforms", Research in Organizational Behavior, Vol. 30, pp. 3-34.

Feldt, G. (2012), No Excuses: Nine Ways Women Can Change How We Think About Power, Seal Press, New York, NY.

Fitzgerald, L. (2021), "Unseen: the sexual harassment of low-income women in America”, Equality, Diversity and Inclusion: An International Journal.

Fitzgerald, L.F., Shullman, S.L., Bailey, N., Richards, M., Swecker, J., Gold, Y., Ormerod, M. and Weitzman, L. (1988), "The incidence and dimensions of sexual harassment in academia and the workplace", Journal of Vocational Behavior, Vol. 32 No. 2, pp. 152-175. 
Fitzgerald, L.F., Gelfand, M.J. and Drasgow, F. (1995), "Measuring sexual harassment: theoretical and psychometric advances", Basic and Applied Social Psychology, Vol. 17, pp. 425-445.

Fitzgerald, L.F., Drasgow, F. and Magley, V.J. (1999), "Sexual harassment in the armed forces: a test of an integrated model", Military Psychology, Vol. 11 No. 3, pp. 329-343.

Folke, O., Rickne, J., Tanaka, S. and Tateishi, Y. (2020), "Sexual harassment of women leaders", Daedalus, (Cambridge, Mass.), Vol. 149 No. 1, pp. 180-197, doi: 10.1162/daed_a_01781.

Franke, K.M. (1997), "What's wrong with sexual harassment?", Stanford Law Review, Vol. 49, pp. 691-772.

Glick, P., Berdahl, J.L. and Alonso, N.M. (2018), "Development and validation of the masculinity contest culture scale", Journal of Social Issues, Vol. 74 No. 3, pp. 449-476.

Glomb, T.M., Munson, L.J., Hulin, C.L., Bergman, M.E. and Drasgow, F. (1999), "Structural equation models of sexual harassment: longitudinal explorations and cross-sectional generalizations", Journal of Applied Psychology, Vol. 84 No. 1, pp. 14-28.

Goh, J.X., Bandt-Law, B., Cheek, N.N., Sinclair, S. and Kaiser, C.R. (2021), "Narrow prototypes and neglected victims: understanding perceptions of sexual harassment", Journal of Personality and Social Psychology.

Gruber, J.E. (1998), “The impact of male work environments and organizational policies on women's experiences of sexual harassment", Gender and Society, Vol. 12 No. 3, pp. 301-320.

Heck, S.E. (2020), "From Anita Hill to Christine Blasey Ford: a reflection on lessons learned", Equality, Diversity and Inclusion: An International Journal, Vol. 39 No. 1, pp. 101-108.

Hershcovis, M.S., Vranjes, I., Berdahl, J.L. and Cortina, L.M. (2021), "See no evil, hear no evil, speak no evil: theorizing network silence around sexual harassment", Journal of Applied Psychology.

Holland, K.J. and Cortina, L.M. (2013), "When sexism and feminism collide: the sexual harassment of feminist working women”, Psychology of Women Quarterly, Vol. 37 No. 2, pp. 192-208.

Hurtado, A. (1989), "Relating to privilege: seduction and rejection in the subordination of white women and women of color", Signs: Journal of Women in Culture and Society, Vol. 14 No. 4, pp. 833-855.

Karam, C.M. and Ghanan (2021), "Multilevel power dynamics shaping employer anti-sexual harassment efforts in Lebanon", Equality, Diversity, and Inclusion.

Kasumovic, M.M. and Kuznekoff, J.H. (2015), "Insights into sexism: male status and performance moderates female-directed hostile and amicable behaviour", PloS One, Vol. 10 No. 7, p. e0131613.

Kellogg, K.C. (2011), Challenging Operations: Medical Reform and Resistance in Surgery, University of Chicago Press, Chicago.

Klein, O., Arnal, C., Eagan, S., Bernard, P. and Gervais, S.J. (2021), "Does tipping facilitate sexual objectification? The effect of tips on sexual harassment of bar and restaurant servers", Equality, Diversity and Inclusion: An International Journal.

Koc, Y., Gulseren, D. and Lyubykh, Z. (2021), "Masculinity contest culture reduces organizational citizenship behaviors through decreased organizational identification", Journal of Experimental Psychology-Applied.

Konik, J. and Cortina, L.M. (2008), "Policing gender at work: intersections of harassment based on sex and sexuality", Social Justice Research, Vol. 21 No. 3, pp. 313-337.

Kossek, E.E., Hammer, L.B., Kelly, E.L. and Moen, P. (2014), "Designing work, family and health organizational change initiatives", Organizational Dynamics, Vol. 43 No. 1, pp. 53-63.

Lang, D.L. and Dallaire, R.A. (2013), "Conduct becoming: why the royal Canadian mounted police must transform its culture", Final report of the Standing Senate Committee on National Security and Defence, available at: https://sencanada.ca/Content/SEN/Committee/411/secd/rep/ rep14jun13-e.pdf (accessed 23 March 2021).
Four ways forward 
EDI

40,4

Leopold, J., Lambert, J.R., Ogunyomi, I.O. and Bell, M.P. (2021), “The hashtag heard round the world: how \#MeToo did whatlaws did not", Equality, Diversity and Inclusion: An International Journal.

Leskinen, E.A., Cortina, L.M. and Kabat, D.B. (2011), "Gender harassment: broadening our understanding of sex-based harassment at work", Law and Human Behavior, Vol. 35, pp. 25-39.

Lim, S. and Cortina, L.M. (2005), "Interpersonal mistreatment in the workplace: the interface and impact of general incivility and sexual harassment", Journal of Applied Psychology, Vol. 90 No. 3, pp. 483-496.

Maass, A., Cadinu, M., Guarnieri, G. and Grasselli, A. (2003), "Sexual harassment under social identity threat: the computer harassment paradigm", Journal of Personality and Social Psychology, Vol. 85 No. 5, pp. 853-870.

MacKinnon, C.A. (1976), Sexual Harassment of Working Women: A Case of Sex Discrimination, Yale University Press, New Haven.

Mansfield, P.K., Koch, P.B., Henderson, J., Vicary, J.R., Cohn, M. and Young, E.W. (1991), "The job climate for women in traditionally male blue-collar occupations", Sex Roles, Vol. 25 No. 1, pp. 63-79.

Matos, K., O’Neill, O. and Lei, X. (2018), “Toxic leadership and the masculinity contest culture: how "win or die" cultures breed abusive leadership", Journal of Social Issues, Vol. 74 No. 3, pp. 500-528.

Mayer, J. (2017), "Anita Hill on Weinstein, Trump, and a Watershed moment for sexual-harassment accusations", The New Yorker, 1 November, available at: https://www.newyorker.com/news/ news-desk/anita-hill-on-weinstein-trump-and-a-watershed-moment-for-sexual-harassmentaccusations (accessed 18 March 2021).

McCall, L. (2005), "The complexity of intersectionality", Signs: Journal of women in culture and society, Vol. 30 No. 3, pp. 1771-1800.

McCluney, C.L. and Rabelo, V.C. (2019), "Conditions of visibility: an intersectional examination of Black women's belongingness and distinctiveness at work", Journal of Vocational Behavior, Vol. 113, pp. 143-152.

McLaughlin, H., Uggen, C. and Blackstone, A. (2012), "Sexual harassment, workplace authority, and the paradox of power", American Sociological Review, Vol. 77 No. 4, pp. 625-647.

Merlo, J. (2013), No One to Tell: Breaking My Silence on Life in the RCMP, Breakwater Books, St. Johns, NL.

National Academies of Sciences, Engineering and Medicine (2018), Sexual Harassment of Women: Climate, Culture and Consequences in Academic Sciences, Engineering, and Medicine, The National Academies Press, Washington, DC.

New York Times (2016), “Transcript: Donald Trump's taped comments about women”, available at: https://www.nytimes.com/2016/10/08/us/donald-trump-tape-transcript.html? (accessed 18 March 2021).

O’Reilly, J., Robinson, S.L., Berdahl, J.L. and Banki, S. (2015), "Is negative attention better than no attention? The comparative effects of ostracism and harassment at work", Organization Science, Vol. 26 No. 3, pp. 774-793.

Perlow, L.A. (2012), Sleeping with Your Smartphone: How to Break the 24/7 Habit and Change the Way You Work, Harvard Business Press, Boston, MA.

Perry, E.L., Block, C.J. and Noumair, D.A. (2021), "Leading in: inclusive leadership, inclusive climates and sexual harassment", Equality, Diversity and Inclusion: An International Journal.

Potter, C. (2018), "Sexual harassment is about power, why not fight it as we do bullying?", The Guardian, available at: https://www.theguardian.com/commentisfree/2018/feb/10/sexualharassment-power-bullying-metoo.

Purdie-Vaughns, V. and Eibach, R.P. (2008), "Intersectional invisibility: the distinctive advantages and disadvantages of multiple subordinate-group identities", Sex Roles, Vol. 59 No. 5, pp. 377-391. 
Robotham, K. and Cortina, L. (2020), "Promoting respect as a solution to workplace harassment", Equality, Diversity and Inclusion: An International Journal.

Rosette, A.S., Koval, C.Z., Ma, A. and Livingston, R. (2016), "Race matters for women leaders: intersectional effects on agentic deficiencies and penalties", The Leadership Quarterly, Vol. 27 No. 3, pp. 429-445.

Sambaraju, R. (2020), "I would have taken this to my grave, like most women": reporting sexual harassment during the\# MeToo movement in India”, Journal of Social Issues, Vol. 76 No. 3, pp. 603-631.

Schneider, K.T. and Carpenter, N.J. (2020), "Sharing\# MeToo on Twitter: incidents, coping responses, and social reactions", Equality, Diversity and Inclusion: An International Journal, Vol. 39 No. 1, pp. 87-100, doi: 10.1108/EDI-09-2018-0161.

Semuels, A. (2002), "TIME persons of the year: The Whistleblowers", TIME, available at: https://time. com/5793757/the-whistleblowers-100-women-of-the-year/ (accessed 18 March 2021).

Shields, S.A. (2008), "Gender: an intersectionality perspective”, Sex Roles, Vol. 59 No. 5, pp. 301-311.

Shute, R., Owens, L. and Slee, P. (2008), "Everyday victimization of adolescent girls by boys: sexual harassment, bullying or aggression?”, Sex Roles, Vol. 58, pp. 477-489.

Sidanius, J. and Pratto, F. (2001), Social Dominance: An Intergroup Theory of Social Hierarchy and Oppression, Cambridge University Press, Cambridge.

Siebler, F., Sabelus, S. and Bohner, G. (2008), "A refined computer harassment paradigm: validation, and test of hypotheses about target characteristics", Psychology of Women Quarterly, Vol. 32 No. 1, pp. 22-35.

Silverschanz, P., Cortina, L.M., Konik, J. and Magley, V.J. (2008), "Slurs, snubs, and queer jokes: incidence and impact of heterosexist harassment in academia", Sex Roles, Vol. 58 No. 3, pp. 179-191.

Smith, A.N., Watkins, M.B., Ladge, J.J. and Carlton, P. (2019), "Making the invisible visible: paradoxical effects of intersectional invisibility on the career experiences of executive Black women”, Academy of Management Journal, Vol. 62 No. 6, pp. 1705-1734.

Stockdale, M.S. (2005), "The sexual harassment of men: articulating the approach-rejection distinction in sexual harassment motives", in Gruber, J.E. and Morgan, P. (Eds), In the Company of Men: Re-discovering the Links between Sexual Harassment and Male Domination, Northeastern University Press, Boston, MA, pp. 117-142.

Stockdale, M.S., Visio, M. and Batra, L. (1999), "The sexual harassment of men: evidence for a broader theory of sexual harassment and sex discrimination”, Psychology, Public Policy, and Law, Vol. 5, pp. 630-664.

Stockdale, M.S., Bell, M.P., Crosby, F.J. and Berdahl, J.L. (2020a), "Guest editorial: from me too to what now: advancing scholarship on sex harassment issue 1: a persistent problem", Equality, Diversity, and Inclusion, Vol. 39 No. 1, pp. 1-4, doi: 10.1108/EDI-02-2020-296.

Stockdale, M.S., Gilmer, D.O. and Dinh, T.K. (2020b), "Dual effects of self-focused and other-focused power on sexual harassment intentions", Equality, Diversity and Inclusion: An International Journal, Vol. 39 No. 1, pp. 17-37, doi: 10.1108/EDI-09-2018-0160.

Studd, M.V. and Gattiker, U.E. (1991), "The evolutionary psychology of sexual harassment in organizations", Ethology and Sociobiology, Vol. 12, pp. 249-290.

Trades Union Congress (2019), "Sexual harassment of LGBT people in the workplace", available at: https://www.tuc. org.uk/research-analysis/reports/sexual-harassment-lgbt-people-workplace? single $=1$ (accessed 18 March 2021).

Uggen, C. and Blackstone, A. (2004), "Sexual harassment as a gendered expression of power", American Sociological Review, Vol. 69 No. 1, pp. 64-92.

Waldo, C.R., Berdahl, J.L. and Fitzgerald, L.F. (1998), “Are men sexually harassed? If so, by whom?”, Law and Human Behavior, Vol. 22 No. 1, pp. 59-79.

Four ways forward 
EDI

40,4
Waugh, I.M. (2010), "Examining the sexual harassment experiences of Mexican immigrant farmworking women", Violence Against Women, Vol. 16, pp. 237-261.

West, C. and Zimmerman, D.H. (1987), “Doing gender”, Gender and Society, Vol. 1 No. 2, pp. 125-151.

Woods, K.C., Buchanan, N.T. and Settles, I.H. (2009), "Sexual harassment across the color line: experiences and outcomes of cross- versus intraracial sexual harassment among black women", Cultural Diversity and Ethnic Minority Psychology, Vol. 15, pp. 67-76.

Workman-Stark, A.L. (2020), "Exploring differing experiences of a masculinity contest culture in policing and the impact on individual and organizational outcomes", Police Quarterly. doi: $10.1177 / 1098611120976090$.

Zacharek, S., Dockterman, E. and Edwards, H.S. (2017), "TIME person of the year: the silence breakers", TIME, available at: https:/time.com/time-person-of-the-year-2017-silence-breakers/ (accessed 18 March 2020).

\section{Corresponding author}

Jennifer Berdahl can be contacted at: jennifer.berdahl@ubc.ca

For instructions on how to order reprints of this article, please visit our website: 